\title{
En la mejor de las circunstancias: ONUSAL y los desafíos de la verificación y el fortalecimiento institucional en El Salvador
}

\author{
David Holiday y William Stanley*
}

\section{Resumen}

El presente artículo se realizó entre 1992 y 1995 . Expone las razones que motivaron a los protagonistas de El Salvador a negociar la paz y abandonar algunos de sus compromisos más importantes. En este sentido, analiza los problemas enfrentados por la Organización de las Naciones Unidas en su función dual, es decir, como verificadora, contraria a su papel previo como mediadora, y en el fortalecimiento institucional. Asimismo se estudian las decisiones que tomó ONUSAL respecto a esta problemática. Los autores sostienen que la postura de las Naciones Unidas, que se basa en principios, generó resultados positivos para el fortalecimiento de la paz en El Salvador, y que la asociación de funciones de verificación y fortalecimiento institucional puede ser favorable si coincide desde el punto de vista político. Finalmente reconocen que los resultados obtenidos fueron determinados, en mayor medida, por las fuerzas políticas nacionales.

* Las investigaciones para este trabajo se realizaron en El Salvador, Washington, D.C. y Nueva York, entre 1992 y 1995. El trabajo de campo fue financiado por el Instituto de la Paz de los Estados Unidos (USIP), y se obtuvo financiamiento adicional del Gene Gallegos Regents' Lectureship de la Universidad de Nuevo México. Los autores desean expresar su agradecimiento a Cynthia Amson, Diego García Sayan, Mark Peceny, Thomas Weiss y a los editores del North-South Center de la Universidad de Miami por sus comentarios a las versiones anteriores. Todas las opiniones expresadas en este documento son responsabilidad exclusiva de los autores. Muchos de nuestros informantes, incluyendo funcionarios de las Naciones Unidas, solicitaron que sus comentarios permanecieran en el anonimato. 


\section{Introducción}

En febrero de 1992, después de trece años, por fin terminó la guerra civil en El Salvador. Después de un cese al fuego de once meses, durante el cual el Frente Farabundo Martí para la Liberación Nacional (FMLN) desmovilizó a su ejército guerrillero, los ex rebeldes formaron su propio partido político. En las elecciones de marzo y abril de 1994, el FMLN obtuvo una representación minoritaria en la asamblea legislativa, mientras el partido oficial Alianza Republicana Nacional (ARENA) obtuvo la presidencia y la mayoría de los escaños. El final de la guerra y la transición de la postguerra del país hacia lo que se presenta como una democracia ampliamente competitiva, se encuentran entre los logros políticos recientes más dramáticos y positivos del hemisferio occidental.

El cese al fuego empezó después de dos años de negociaciones, las cuales dieron origen a una serie compleja de acuerdos para introducir reformas fundamentales en las instituciones del Estado salvadoreño. Inicialmente la Organización de las Naciones Unidas facilitó las negociaciones por medio de sus buenos oficios y luego continuó desempeñándose como mediador más activo. Sus mediadores incluso apoyaron la redacción de los acuerdos. Entre los acuerdos más importantes se encuentran las reformas constitucionales y de la legislación secundaria, las cuales limitaron de manera definida la función de la Fuerza Armada en cuanto a la seguridad pública, establecieron una nueva fuerza conformada en la Policía Nacional Civil y crearon una Procuraduría para la Defensa de los Derechos Humanos.

Los acuerdos también estipularon reformas más limitadas en los sistemas judicial y electoral así como también otras medidas como la transferencia de tierras, la capacitación y el crédito para ayudar a los ex combatientes a reincorporarse en la vida civil. Los acuerdos invitaban a las Nacio- nes Unidas a verificar su implementación por medio de una misión de observadores.

En términos generales, la implementación de los acuerdos fue exitosa, aunque hubo muchos reveses en el camino y todavía existen buenas razones para cuestionar si el proceso en su conjunto, finalmente, dará paso a una democracia consolidada o, al menos, a una "revolución lograda a base de negociaciones", como lo describió el Secretario General de las Naciones Unidas, Boutros Boutros Ghali1. El cese al fuego iniciado en febrero de 1992 nunca fue violado, aunque algunos combatientes desmovilizados fueron asesinados posteriormente. Después de algunas demoras e irregularidades iniciales se logró la desmovilización y el desarme de las fuerzas militares de ambas partes. Las Naciones Unidas y otros observadores internacionales consideraron que las elecciones de 1994 fueron suficientemente libres y limpias, a pesar de numerosos problemas técnicos y de organización que se sucitaron y afectaron en particular a los nuevos votantes.

Ahora, más que en ningún otro momento, antes o durante la guerra, los salvadoreños gozan de mayor seguridad respecto al arresto, el abuso o el asesinato arbitrarios por parte de oficinas gubernamentales, pero existen síntomas alarmantes del posible regreso de prácticas autoritarias bajo un nuevo liderazgo civil. Las nuevas instituciones creadas por los acuerdos de paz, como la Policía Nacional Civil y la Procuraduría para la Defensa de los Derechos Humanos, aún son cuestionadas. Ambas han superado obstáculos serios y prometen mucho, pero la primera se ha resistido a la fiscalización pública $y$, en algunas ocasiones, ha reprimido; mientras que la procuraduría ha sido objeto de ataques públicos e ideológicos por parte de opositores internos y externos al gobierno. En general, a pesar de los importantes logros de los acuerdos, la confianza nacional en las instituciones democráticas es débil2.

1. Ver Boutros Boutros Ghali, "La larga noche de El Salvador llega a su fin", discurso pronunciado con motivo de la firma de los acuerdos finales de paz de El Salvador, acto realizado en la ciudad de México, el 16 de enero de 1992. Publicado en español en Acuerdos hacia una nueva nación, San Salvador, FMLN, 1992, p. 151.

2. Comunicado de prensa, Instituto Universitario de Opinión Pública (IUDOP), enero de 1996, basado en una encuesta realizada a finales de 1995. De acuerdo con la misma encuesta, el 76 por ciento de los entrevistados tenía poca o ninguna confianza en los partidos políticos, el 71 por ciento tenía poca o ninguna confianza en la asamblea legislativa, y más del 74 por ciento tenía poca o ninguna confianza en el presidente Calderón. Ver también Richard Stahler-Sholk, "El Salvador's negotiated transition: from low-intensity conflict to low-intensity democracy", Journal of interamerican studies and world affairs, Vol. 36, No 4, 1994, pp. 1-60. 
No obstante la cantidad de preocupaciones actuales, para las Naciones Unidas el resultado obtenido en El Salvador ha sido tan positivo, en comparación con otras intervenciones suyas, que se ha vuelto un ejemplo de lo que ésta es capaz de lograr en este período de postguerra fría. El relativo éxito en El Salvador es aun más significativo porque se trata de uno de los primeros estados afiliados al cual la Organización de las Naciones Unidas intentó ayudar a resolver un conflicto interno, mediante la reconciliación y la "construcción de la paz". Este logro ha contribuido a que en una ocasión Boutros Boutros Ghali, entonces Secretario General de las Naciones Unidas, haya afirmado triunfante, en una conferencia de prensa, en Nueva York: "No se puede subestimar el hecho de que las Naciones Unidas haya sido capaz de resolver los problemas en Cambodia, El Salvador, Mozambique y ahora quizás en Angola3". De hecho, el proceso en El Salvador parece validar, por lo menos superficialmente, la visión del Secretario General, en cuanto a una ONU más activa y capaz de tener un rol significativo en la promoción de la paz interna de los estados afiliados, consolidando las instituciones democráticas 4 .

No cabe duda de que los múltiples roles de las Naciones Unidas como intermediaria, mediadora, verificadora y facilitadora del fortalecimiento institucional fueron cruciales para el éxito del proceso de paz en El Salvador. Sin embargo, la organización también fue extraordinariamente afortunada en este país. Su éxito se puede atribuir tanto a las circunstancias particulares del caso como a las acciones propias. El proceso en El Salvador se llevó a cabo en circunstancias inusualmente fortuitas que, es posible, no se repetirán en otro lado. Ciertos acontecimientos políticos internos únicos y algunas condiciones internacionales especiales generaron en los protagonistas un compromiso profundo y consistente para finalizar la guerra por medio de negociaciones. Aunque ambas partes violaron algunos aspectos de los acuerdos y a veces no cumplieron sus compromisos, en ningún momento, ninguna de ellas llegó al extremo de renunciar al proceso, contrario a lo que sucedí en Cambodia o Angola. El resultado fue un proceso robusto, capaz de sobrevivir a sus irregularidades.

Algunas de las lecciones más importantes que presenta el proceso salvadoreño no radican en su éxito en general, sino en la forma en que la Organización de las Naciones Unidas enfrentó una serie de desafíos difíciles, no obstante el contexto general favorable. Al examinar más de cerca el rol de esta organización, en particular durante la fase de implementación de los acuerdos (1992-1996), se descubre que su influencia en el curso de los acontecimientos, en algunas ocasiones, fue bastante limitada. Hubo resultados importantes que fueron consecuencia de acontecimientos e intereses políticos domésticos fuera del control de la organización internacional. También se dieron muchas tensiones intrínsecas entre los diferentes aspectos del rol "multidisciplinario" de las Naciones Unidas. Los desafíos que ésta enfrentó en El Salvador podrían repetirse con facilidad en otros lados y constituir retos aun más serios, en circunstancias menos positivas.

Este trabajo tiene dos metas. Primero, examinar las motivaciones de los protagonistas en El Salvador para explicar la razón que los impulsaba simultáneamente a lograr y negociar la paz así como a inclinarse a abandonar algunos de sus compromisos más importantes. En este contexto, se analiza una serie de problemas enfrentados por las Naciones Unidas, tanto en la realización de su rol verificador como en sus posteriores tareas de

3. Transcripción de la conferencia de prensa celebrada en las oficinas centrales de las Naciones Unidas, el 5 de enero de 1995, al entregar el Supplement to an agenda for peace.

4. Boutros Boutros Ghali, An agenda for peace (Nueva York, departamento de Información Pública de las Naciones Unidas, 1993); también "Democracy: a newly recognized imperative", Global governance, Vol. 1, № 1, 1995, pp. 3-11.

EN LA MEJOR DE LAS CIRCUNSTANCIAS: ONUSAL 
fortalecimiento institucional. La influencia más importante en ambas partes, a lo largo del proceso, fue el temor igualmente compartido al fracaso. Sin embargo, a fin de evitar socavar la confianza básica de las partes, esta organización debió ser cautelosa para prevenir la incidencia de factores que pudieran amenazar el proceso. El rol verificador de las Naciones Unidas era contrario a su papel previo como mediador, pues los compromisos del gobierno salvadoreño rebasaban en número a los del FMLN, la Organización de las Naciones Unidas criticó más severamente al gobierno que a la guerrilla y, por lo tanto, puso en peligro su imagen de imparcialidad. Esto fue en particular problemático cuando ONUSAL (en su rol verificador) tuvo que criticar a las instituciones del Estado con las cuales pretendía trabajar (en su rol de fortalecimiento institucional).

Además, a esto estaba bastante relacionado el hecho de que ONUSAL encontrase difícil equilibrar su responsabilidad de informar directamente a la población (respecto a los derechos humanos, por ejemplo) versus su necesidad de mantener una relación diplomática confidencial que funcionara con ambas partes. Además de estas cuestiones prioritarias, la Organización de las Naciones Unidas no siempre tuvo capacidad para verificar realmente los aspectos cruciales de los acuerdos, como, por ejemplo, el inventario de armas del FMLN o los traslados de personal militar del gobierno a la nueva policía civil. En otras situaciones, la misión contaba con recursos importantes para ofrecer y decidió intervenir en circunstancias en donde las instituciones nacionales se desempeñaban tan desacertadamente que amenazaban el proceso de paz. También se examinó en qué condiciones pudieron pesar más los beneficios de dicha intervención que el riesgo de fomentar la dependencia.

Asimismo, se analizaron las decisiones tomadas por ONUSAL sobre estas cuestiones, a fin de ilustrar los cambios asociados con cada una de ellas y para sugerir estrategias institucionales y políticas que, hasta cierto punto, podrían haber disminuido el alcance de estos problemas. El éxito mayor de las Naciones Unidas ocurrió cuando ofreció a las partes servicios que éstas no tenían manera de obtener5; cuando interpretó correctamente los intereses políticos de los actores nacionales y de los directores de las instituciones gubernamentales y cuando combinó en forma efectiva la crítica con las ofertas de ayuda condicionada a los actores nacionales para que éstos alcanzaran sus propias metas. También se sostiene que las posturas de esta organización, basadas en principios, produjeron resultados positivos aun cuando ésta no estuviera en posición de imponer sus puntos de vista, y que sus intervenciones para rescatar aquellas instituciones nacionales que habían fracasado pueden ser adecuadas ahí donde resultan vitales para el proceso en general.

\section{Las condiciones nacionales e internacionales para la paz}

\subsection{El compromiso nacional}

A principios de los noventa, las condiciones militares, políticas y económicas -internacionales y nacionales - se combinaron para crear un clima propicio para la paz. No sólo las dos partes del conflicto habían alcanzado un punto de "estanca-

5. Este es un argumento de Kevin Hartigan en relación con el acceso extraordinario brindado al Alto Comisionado de las Naciones Unidas para Refugiados por parte de los gobiernos de México y Honduras. Ver "Matching humanitarian norms with cold, hard interests: the making of refugee politics in Mexico and Honduras, 1980-1989", Intemational organization, Vol. 46, N 3, 1992. 
miento angustiante", sino que habían evolucionado de tal forma que ambas tenían interés en la paz y capacidad para hacerla realidad6. La influencia internacional más obvia fue el colapso de los regímenes europeos orientales, aliados de la Unión Soviética. Aunque estos acontecimientos tuvieron poco efecto inmediato en la capacidad militar de la guerrilla, cuyo sistema ampliamente diversificado de apoyo financiero y logístico le permitió no resentir la pérdida de posibles fuentes, el evidente fracaso político y económico de los sistemas socialistas europeos ocasionó cambios en su posición ideológica. Junto a la derrota electoral del Frente Sandinista en las

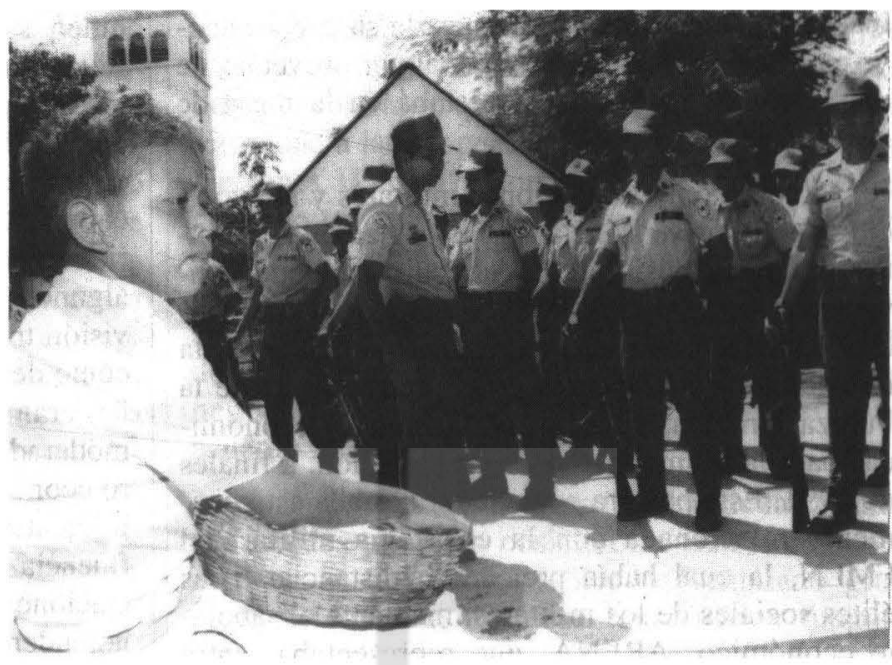
elecciones de 1990, en Nicaragua, los acontecimientos en Europa oriental sugerían al FMLN que sería más efectivo negociar las reformas políticas en vez de apropiarse del poder.

El colapso del bloque oriental, sin embargo, posiblemente fue mayor en los miembros de la élite social conservadora de El Salvador, quienes empezaron a considerar al FMLN, no como una amenaza comunista internacional, sino como un movimiento nacional con el cual era posible negociar. En junio de 1989, el presidente recién electo Alfredo Cristiani, del partido de derecha ARENA, inició una ronda más seria de diálogo, al anunciar en su discurso inaugural que negociaría la paz con el FMLN. En cierto modo fue sorprendente que precisamente el Partido ARENA —organizado a principios de los ochenta por Roberto D'Aubuisson, ex oficial militar y conocido líder de los escuadrones de la muerte - fuera uno de los protagonistas de la paz. A mediados de los ochenta, ARENA inició un proceso de moderación y expansión política, y su éxito en las elecciones de 1988 y 1989 confirmó, más que su dependencia de los militares, su capacidad para defender los intereses de los sectores conservadores de la sociedad en el ámbito electoral y político.

El impulso para negociar con la insurgencia fue reforzado por el hecho de que, después de diez años de guerra, la Fuerza Armada de El Salvador no logró derrotar o contener totalmente al FMLN.

En noviembre de 1989 (después de una inútil ronda de negociaciones, realizada en octubre de 1989), la guerrilla llevó este asunto a donde tenía que llegar y lanzó su mayor ofensiva de toda la guerra, ocupando algunos sectores de la ciudad capital. En medio de la acción, la Fuerza Armada asesinó a seis sacerdotes jesuitas y a dos testigos del hecho en la Universidad Centroamericana "José Simeón Cañas" y, posteriormente, intentó ocultar su crimen.

Esta ofensiva del FMLN influyó positivamente en los ánimos de negociación del gobierno de ARENA. Además, el desempeño deficiente de la Fuerza Armada, al no prepararse de manera adecuada para la ofensiva y al asesinar a los jesuitas, personalidades prominentes a nivel nacional $e$ internacional, la despojó de su antigua capacidad para vetar las negociaciones, tal como había sucedido a mediados de los ochenta y a mediados de 1989. La Fuerza Armada dependía, en gran medida, del suministro constante de repuestos, equipo y municiones de los Estados Unidos. Las perspectivas de ayuda contínua disminuyeron después de la muerte de los jesuitas, lo cual causó un daño irreversible al apoyo político del Congreso de los Estados Unidos al ejército salvadoreño. La ofensiva de noviembre también aumentó la determinación de la dirigencia del FMLN para negociar. El que el FMLN no lograse organizar una insurrección

6. William Y. Zartman, "Ripening conflict, ripe moment, formula, and mediation", en Perspectives on negotiation: four case studies and interpretations. Diane B. Bendahmane y John W. McDonald, Jr. (eds.), Washington, D.C., Foreign Service Institute, Departamento de Estado de los Estados Unidos, 1986, pp. 205-227. 
masiva puso en claro los límites de su propio apoyo político. Si habría de sacar algún provecho de una década de guerra, éste estaba en la mesa de negociación.

El colapso de las opciones militares y la evolución de las circunstancias políticas nacionales e internacionales posibilitaron la realización de conversaciones serias. El FMLN enfocó sus exigencias en la reforma del Estado, en particular en la reduccion de los poderes y las prerrogativas de la Fuerza Armada, dejando las cuestiones económicas para la última fase de la negociación, a finales de 1991. Esta postura negociadora estaba estrechamente relacionada con la estrategia militar del FMLN, la cual había pretendido distanciar a las élites sociales de los militares, mediante el sabotaje económico. ARENA, que representaba, entre otros grupos, a la mayor parte de la empresa privada del país, tenía mucho que ganar en la negociación y relativamente poco que perder. Un acuerdo de paz acabaría con el sabotaje guerrillero, abriendo nuevas posibilidades para la recuperación económica y la inversión. Las exigencias de la guerrilla respecto a la Fuerza Armada podrían ser aceptables, porque la utilidad de ésta como defensora del orden de todas formas estaba siendo cuestionada por los sectores conservadores. Con su poderosa maquinaria electoral, ARENA tenía buenas razones para confiar en su capacidad para mantener su posición en unas elecciones futuras donde participaría el FMLN.

La lógica política para llegar a un acuerdo estaba reforzada por los cambios económicos, forjados por la guerra misma. La lucha y las amenazas de la guerrilla habían alejado de sus tierras a muchos agroexportadores de mediana y gran escala. Muchos sacaron su capital del país o lo trasladaron al comercio, los servicios financieros, la construcción y la industria?. La caída repentina de los precios internacionales del café debilitó aún más al sector agrícola y contribuyó a que los recursos se continuaran desviando hacia otras actividades. Elizabeth Wood coincide con Barrington Moore, quien sostiene que lo más probable es que los miembros de las élites agrícolas tiendan más a formas de gobierno coercitivo que las industriales y comerciales urbanas. A su vez, Wood afirma que el gran cambio de los intereses económicos de los capitalistas salvadoreños debilitó su postura históricamente antidemocrática y promilitar ${ }^{8}$. Aunque algunos sectores de la élite siguieron fieles a su vision tradicional represiva y militarista respecto a cómo debería ser gobernada la sociedad salvadoreña, eran cada vez menos numerosos que los más moderados dentro de ARENA y su propio deterioro económico continuó debilitando su posición política. El cambio generacional y la creciente influencia de los empresarios medianos en las asociaciones del sector privado continuó reforzando la tendencia hacia la moderación política9.

\subsection{La mediación internacional, verificación e influencia}

Aunque ambas partes estaban comprometidas en la negociación de la paz, la desconfianza fundamental entre ellas representaba un obstáculo prácticamente insuperable para la reconciliación.

Aquí la función de las Naciones Unidas fue esencial. Como intermediaria y posteriormente como verificadora de los acuerdos hizo posible que los antagonistas confiaran en el proceso de paz, aunque no confiaran en el otro. En diciembre de 1989, el FMLN y el gobierno de Cristiani se acercaron por separado a este organismo buscando apoyo. El representante especial del Secretario General de las Naciones Unidas, Alvaro de Soto, respondió favorablemente a las propuestas.

A lo largo de los dos años siguientes, las partes firmaron seis acuerdos por separado: en los acuerdos de abril de 1990, en Ginebra, ambas se comprometieron a mantener negociaciones contínuas y secretas con la mediación de las Naciones Unidas; en los acuerdos de mayo de 1990, en Caracas, se definió una agenda para las conversaciones siguientes; en los acuerdos sobre derechos humanos,

7. Lawyers Committee for Human Rights, Improvising history: a critical evaluation of the United Nations Observer Mission in El Salvador, Nueva York: Lawyers Committee for Human Rights, 1995, p.6; entrevista con el ex coordinador del FMLN, Shafick Handal, julio de 1995.

8. Entrevistas con funcionarios de las Naciones Unidas, octubre de 1992 y abril de 1995.

9. Como explicaremos en detalle a continuación, el acceso de ONUSAL a dichos roles de verificación y fortalecimiento institucional con la Polića Nacional Civil fue discontinuo y agitado. 
firmados en julio de 1990, en San José, se definió el primer mandato específico de las Naciones Unidas (verificación de los derechos humanos) así como los poderes extraordinariamente amplios para que una futura misión de observación de este organismo investigara en El Salvador; en abril de 1991, en México, se firmaron los acuerdos sobre la reforma constitucional y una comisión de la verdad para investigar actos de violencia; en septiembre de 1991, en Nueva York, se firmaron los acuerdos que establecían la creación de una fuerza pública civil y una Comisión para la Consolidación de la Paz (COPAZ) dedicada a verificar los acuerdos; los acuerdos finales se firmaron en el Castillo de Chapultepec, en México, el 16 de enero de 1992.

Durante este proceso, el rol de la Organización de las Naciones Unidas se volvió cada vez más importante. Los acuerdos de San José resultaron de una sugerencia de ella. En efecto, este organismo sostenía que un acuerdo sobre derechos humanos podría ayudar a mantener el entusiasmo, a pesar del estancamiento de la reforma militar y del compromiso mutuo de rendir cuentas sobre los abusos del pasado. El acuerdo íntegro fue redactado por Pedro Nikken, experto de las Naciones Unidas sobre derechos humanos (quien se baso en varias sesiones preparatorias con expertos internacionales de derechos humanos y organizaciones no gubernamentales, las cuales habian sido convocadas con anterioridad por las Naciones Unidas), y fue firmado prácticamente sin modificaciones por las partes 10 .

Después de San José, Alvaro de Soto y su equipo de consejeros asumieron un rol cada vez más activo en las negociaciones. Con el fin de ayudar a superar los vetos mutuos de las partes, la Organización de las Naciones Unidas empezó a preparar documentos de trabajo, compilando las propuestas fundamentales de ambas. Los negociadores encontraron que las dos concedían mayor legitimidad a las propuestas si éstas provenían de las Naciones Unidas 10. Con la mediación de ésta, la cual fue tan importante para el proceso, a finales de 1991, la inminente salida de su secretario general, Javier Pérez de Cuéllar, puso mayor presión sobre las partes. Junto con la presión de los Estados Unidos, esta fecha límite ayudó a acelerar las negociaciones, entre septiembre de 1991 y el acuerdo final.

A fin de cuentas, la Organización de las Naciones Unidas tuvo una posición inusualmente poderosa en El Salvador. Habiendo formulado gran parte de los acuerdos, sus funcionarios fungían como intérpretes rigurosos de lo que los acuerdos exigían a cada parte. Además, los acuerdos mismos otorgaban amplios poderes a la misión de esta organización, la cual, incluso, tenía autoridad general para verificar y velar por el cumplimiento de las obligaciones de ambas partes; regular los movimientos de las fuerzas militares de las dos partes; acompañar a la antigua Policía Nacional durante la transición a la nueva Policía Nacional Civil; ayudar a proveer seguridad pública durante la transición en zonas previamente conflictivas; evaluar el contenido de la doctrina y educación militar; investigar los casos de derechos humanos y certificar el estado de las armas del FMLN. Una invitación posterior del gobierno la facultó para supervisar y evaluar la imparcialidad de las campañas electorales, el empadronamiento y las elecciones. El gobierno también la invitó a asumir una serie de roles adicionales, incluyendo varias evaluaciones de la Policía Nacional Civil así como la instrucción práctica de los agentes recién graduados de la Academia Nacional de Seguridad Públicall.

10. Entrevistas con funcionarios de las Naciones Unidas, septiembre y noviembre de 1992.

11. Entrevistas con miembros locales de la Resistencia Nacional (anteriormente FMLN), junio de 1995; Banco Gubernamental de tierras y funcionarios de la oficina de transferencia de tierras, septiembre de 1992 y junio de 1995 . La frustración por parte de los líderes del FMLN y sus seguidores era justificada: la implementación del programa de 
El hecho de que el gobierno tuviera tantas tareas que llevar a cabo después de la desmovilización del FMLN significaba que la implementación de los acuerdos de paz dependía mucho del ánimo de cooperación de éste y de la habilidad de las Naciones Unidas para hacerlos cumplir. Esta pudo asumir la responsabilidad por su capacidad para influenciar las ayudas que los donantes extranjeros podían dar al gobierno salvadoreño para la reconstrucción. Aunque la propia misión de Observación de las Naciones Unidas en El Salvador (ONUSAL) no controlaba ni administraba los fondos de reconstrucción importantes, las naciones donantes esperaban que ella y la secretaría de las Naciones Unidas evaluaran el compromiso del gobierno con el proceso12. Una evaluación negativa de ONUSAL podía disminuir seriamente el monto de la ayuda otorgada para el desarrollo y la reconstrucción.

\subsection{Los incentivos nacionales para violar los acuerdos}

Anticipando las elecciones de 1994, tanto el FMLN como ARENA necesitaban mantener consolidadas sus respectivas bases de apoyo político, mientras preservaban una imagen pública positiva, que les posibilitara atraer los votos de los indecisos o abstencionistas. Estas metas contradecían potencialmente las concesiones que ambas partes habían hecho en los acuerdos. Muchos de los conflictos que enfrentó ONUSAL fueron producto de los esfuerzos del gobiemo y del FMLN para obstaculizar la implementación de disposiciones que podrían causar el distanciamiento de partidarios importantes o de maniobras para maximizar los beneficios para sus propios seguidores. En muchas ocasiones, los costos internacionales por adoptar medidas contrarias a la voluntad de ONUSAL resultaron ser menos apremiantes para las partes que los incentivos nacionales para seguir adelante. Esta limitación fundamental del poder de las $\mathrm{Na}$ ciones Unidas constituyó la base de la mayoría de los desafíos que ONUSAL tuvo que enfrentar al cumplir con su mandato. Aquellas decisiones de las partes criticadas por el secretario general de este organismo por denotar falta de "voluntad política", en realidad demostraron la fuerte voluntad política de éstas para alcanzar sus propios intereses, no obstante las prioridades de la misión.

La misma estrategia que permitió al FMLN la negociación exitosa de un tratado de paz con el gobierno de ARENA también le creo serias desventajas políticas. Al concentrar sus demandas en la desmilitarización y las reformas institucionales, el FMLN corría el riesgo de alienar a sus partidarios políticos más leales en las áreas rurales. A lo largo de la guerra, el FMLN había afirmado que con su lucha pretendía corregir las injusticias socioeconómicas y su postura evidente en estos temas era una de sus fuentes principales de apoyo popular. Por lo tanto, el FMLN poseía motivos sólidos para impulsar al máximo la implementación de las medidas económicas de los acuerdos (que eran las más lentas), al punto de orquestar ocupaciones de tierras y presentar listas abultadas de propiedades y de sus respectivos ocupantes, todo ello con el propósito de maximizar la cantidad de tierra concedida a sus partidarios 13 .

El FMLN adoptó otras medidas perjudiciales para llevar al máximo los beneficios de sus combatientes. Algunos de sus comandantes de tropa postergaron la desmovilización de sus fuerzas hasta que los donantes internacionales prometieran fi-

transferencia de tierras fue impedida por problemas legales y derechos extremadamente complejos, por la resistencia del gobierno, las instituciones incompetentes para la implementación, los déficits financieros intermitentes, la carencia de propietarios dispuestos a vender su tierra y las complicaciones de los procedimientos que eran una pesadilla y que disuadían hasta a los propietarios que inicialmente estaban deseosos de vender. La transferencia de tierras no se completó sino hasta mediados de 1996, cuatro años después de haberse iniciado, y eso a pesar de las repetidas medidas tomadas por las Naciones Unidas para mantener el proceso en marcha.

12. El gobierno no aceptó formalmente el Plan 600, sino hasta febrero de 1993, después de la desmovilización del FMLN, en diciembre de 1992. Sin embargo, los donantes internacionales habían comprometido fondos informalmente antes de la desmovilización de éste y la documentación interna de la Secretarfa de Reconstrucción Nacional contemplaba el Plan 600 desde diciembre de 1992.

13. Estas incluían reducir sus prerrogativas constitucionales, finalizar sus roles políticos fundamentales en la seguridad y la inteligencia domésticas, disolver tres cuerpos de seguridad historicamente represivos y políticamente conservadores, imponiendo una supervisión civil parcial sobre la academia militar, y exponiendo a los oficiales militares a la evaluación y la crítica externa (civil). 
nanciar un programa especial de becas, capacitación y préstamos para los comandantes de nivel medio, a lo cual posteriormente se le denominó el "Plan 600 "14. En algunas ocasiones, la búsqueda de beneficios mayores llevó al FMLN a adoptar actitudes comprometedoras en asuntos que la Organización de las Naciones Unidas hubiera preferido implementar más estrictamente: algunos grupos del FMLN acordaron demorar la depuración de los oficiales militares de alto nivel y aceptar el traslado de ciertas unidades militares a la policía civil (ver más adelante) a cambio de algunas consideraciones económicas en forma de tierras y mejores programas de reinserción.

El gobierno, por su parte, al firmar los acuerdos de paz aceptó un conjunto diferente de responsabilidades políticas. Como se observó anteriormente, el mayor peso de los acuerdos estaba en lo militar ${ }^{13}$.

Estas medidas fueron necesarias para llegar a un acuerdo con el FMLN, aunque las mismas implicaban una gran brecha entre ARENA y los militares, quienes, a pesar de las tensiones y las sospechas mutuas a lo largo de los años, poseían nexos personales e ideológicos estrechos entre sí. Los militares y las antiguas fuerzas de seguridad pública, no obstante todas las violaciones que cometieron durante la guerra civil, defendieron históricamente los intereses de los grupos sociales elitistas que ayudaron a fundar ARENA, y parte del apoyo de base de este partido y de su liderazgo mantenían fuertes relaciones de lealtad personal con la Fuerza Armada. Existra el riesgo de que, a consecuencia de los acuerdos, ARENA enfrentara divisiones internas, especialmente si la implementación de algunas de las disposiciones humillaba a la institución armada o a su dirigencia. También, existía el riesgo de que algunos elementos militares, si eran presionados, desafiaran abiertamente el control civil. Por lo tanto, ARENA tenía motivos para implementar lo menos posible las disposiciones militares de los acuerdos.

Uno de los primeros problemas que esta perspectiva creó al proceso de paz fue el manejo de la desmovilización de la Guardia Nacional y de la Policía de Hacienda, las cuales fueron meramente rebautizadas por el gobierno y trasladadas directamente al ejército. De hecho, los acuerdos estipulaban su traslado, más que su desmovilización total como el FMLN hizo creer a muchos; pero la legislación vigente no estipulaba claramente que estos cuerpos dejarían de tener funciones de seguridad pública. Solamente después de las objeciones del FMLN y de las críticas de ONUSAL, el gobierno dio una "interpretación auténtica" de la ley, aclarando que estas fuerzas ya no tenían funciones policiales. El gobierno también tardó en crear la nueva fuerza pública civil. La academia abrió sus puertas con un retraso de cuatro meses, en parte, porque el programa original estableció un plazo irrealmente corto $y$, en parte, porque el gobierno no pidio a los militares que cedieran las instalaciones necesarias para su funcionamiento 14 . Las tensiones sobre los asuntos militares se avivaron cuando la Comisión ad hoc, encargada de evaluar los expedientes de los oficiales, envió al secretario general de Naciones Unidas una lista de 103 oficiales, donde, según parece, se incluía prácticamente al alto mando en pleno15. El gobiemo no ejecutó estas recomendaciones en el tiempo previsto y en repetidas ocasiones solicitó prórrogas para cumplirlas al secretario general de las Nacio-

14. Cuando se fundó la academia, pronto se descubrí que el gobiemo habra presentado una cantidad de oficiales militares que eran evidentemente inelegibles como candidatos para puestos de mando en la Policfa Nacional Civil.

15. Esta recomendación fue mucho más fuerte de lo que esperaba la mayorla de observadores, ya que los miembros de la Comisión ad hoc eran todos salvadoreños y nadie parece haber esperado que tuvieran valor para solicitar una depuración tan radical de los oficiales del más alto nivel. 
nes Unidas. Esta no certificó el cumplimiento de las obligaciones del gobierno, sino hasta a principios de julio de 199316.

Obviamente, el impacto de los acuerdos en el gobierno no fue exclusivamente negativo. Por el contrario, los acuerdos también brindaron al gobierno oportunidades importantes para crear capital político. El presidente Cristiani proyectó una imagen muy positiva de sí mismo como el "presidente de la paz" y el país obtuvo ayuda internacional significativa, aumentando los recursos gubernamentales disponibles en un momento de ajustes estructurales y reduciendo los costos políticos que normalmente se asocian con las medidas de austeridad 17 .

En efecto, los programas internacionales identificados con el proceso de paz ayudaron proporcionando una red de seguridad social que, de otra manera, no hubiera existido o hubiera tenido que ser financiada por el gobierno. También se obtuvieron beneficios a expensas del FMLN y de otros grupos opuestos al gobierno. Tanto los observadores locales como los internacionales criticaron el plan de reconstrucción nacional del gobierno por su parcialidad, su predisposición ante las organizaciones no gubernamentales independientes y dependientes del FMLN y por favorecer aquellas áreas del país que se esperaba apoyarían más al gobierno en las elecciones inminentes. Los acuerdos conminaban al gobierno a administrar el plan de reconstrucción nacional de tal modo que promoviera la reconciliación nacional pero, en la práctica, éste se convirtió en un instrumento de influencia política, que discriminó en contra de aquellas zonas o comunidades que no estaban bajo el control firme de ARENA. Las agencias seleccionadas para implementar el plan a menudo no eran las más capaces y los programas concretos no se adaptaban adecuadamente a las necesidades socioeconómicas de los pobres 18 .

En general, el proceso de paz de El Salvador se caracterizó por condiciones internacionales y nacionales inusualmente afortunadas, y también por los poderes únicos que tuvo la Organización de las Naciones Unidas. Sin embargo, hubo obstáculos políticos nacionales significativos y, a fin de cuentas, el poder de este organismo fue limitado en cuanto al control de la autonomía esencial de los antagonistas salvadoreños. En la sección siguiente se examina cómo trabajó esta organización en el marco de dichas limitaciones.

\section{Los desafios para las Naciones Unidas: la verificación}

\subsection{La imparcialidad}

Tal como se ilustró en la discusión anterior, las dos partes de los acuerdos estaban fuertemente motivadas a violarlos o a distorsionar su significado en beneficio propio. Al mismo tiempo, ambas estaban extremadamente motivadas a evitar que el proceso de paz fracasara y ambas necesitaban mantener imágenes internacionales positivas y contar con la aprobación de los donantes extranjeros. La influencia de la verificación de las Naciones Unidas se basó en estas dos preocupaciones de las partes. Sin embargo, no era conveniente que esta última denunciara una cantidad ilimitada de violaciones a los acuerdos, porque podía ponerlos en serio peligro, ya que las denuncias frecuentes sobre situaciones que amenazaban la estabilidad del proceso podían llegar a acostumbrar a las partes 0 , de hecho, minar la confianza, lo cual podía llegar a tener consecuencias impredecibles.

Uno de los dilemas más importante enfrentados por ONUSAL fue mencionado en términos más generales por el subsecretario general, Marrack Goulding, en 1993, al referirse a las opciones que Naciones Unidas enfrenta cuando una de las partes incumple un acuerdo.

¿La organización de las Naciones Unidas pue-

16. La Organización de las Naciones Unidas no certificó que el gobiemo había cumplido con sus obligaciones a este respecto hasta principios de julio de 1993. Ver The United Nationes and El Salvador, 1990-1995, Blue Book Series, Vol. 4 (en adelante denominado Blue Book), Nueva York, United Nations Department of Public Information, 1995, Documento 84, p. 471.

17. Entrevista a un funcionario de la embajada de los Estados Unidos, junio de 1995.

18. Ver Kevin Murray et al., Rescuing Reconstruction: the debate on post-war economic recovery in El Salvador, Cambridge y San Salvador: Hemisphere Initiatives, 1994. 
de permanecer imparcial ante ambas partes? ¿Acaso no debería tomar medidas contra la parte infractora para persuadirla u obligarla a cumplir con sus compromisos? Quizás debería ser así. Pero, si este organismo toma ese camino y si la parte infractora la percibe como adversaria, ¿acaso no arriesgaría la cooperación de dicha parte, de la cual podría depender el éxito de la iniciativa entera?19

En El Salvador, la postergación constante de los acuerdos fue responsabilidad del gobierno aunque, en parte, ello se haya debido a la lentitud del flujo de las donaciones extranjeras y a un calendario extremadamente ambicioso. Por lo tanto, ONUSAL estuvo obligada a criticar más al gobierno que al FMLN. Este es el problema que describe Goulding. Sin embargo, durante todo el año 1992, ONUSAL pudo desviar la hostilidad del gobierno, debido al rol indispensable que jugaba en la mediación de los conflictos que tenían lugar entre las partes. De dicha mediación salieron nuevos acuerdos de "recalendarización" de los acuerdos originales, en junio y agosto de 1992, una fórmula de arbitraje obligatorio para resolver el dilema de la transferencia de tierras $y$, finalmente, la recalendarización de la fecha final para la desmovilización del FMLN, el 15 de diciembre de 1992. Sin embargo, ONUSAL solamente estaba en posición de mediar entre ambas partes en la medida en que existiera un equilibrio de fuerzas razonable entre ellas, situación que cambió cuando las fuerzas militares del FMLN se desmovilizaron, a finales de 1992.

El final de la fase del cese al fuego coincidió con una confrontación difícil entre las Naciones Unidas y el gobierno por la implementación de las recomendaciones de la Comisión ad hoc, encargada de la depuración de los militares. El secretario general de las Naciones Unidas, Boutros Ghali, asistió a la ceremonia final de desmovilización, que tuvo lugar en San Salvador, el 15 de diciembre de 1992, sobre la base de una promesa del presidente Cristiani en cuanto a que daría los pasos administrativos necesarios para acatar las recomendaciones de la comisión hasta el 1 de enero de 1993. Durante la primera semana de enero se hizo evidente que Cristiani no había cumplido su promesa.

En este contexto, el debilitado FMLN (tanto militar como politicamente) inició una serie de negociaciones con el gobierno, en las cuales intentó explotar los dos puntos de influencia que le quedaban: la pérdida del apoyo internacional del gobierno por no observar las recomendaciones de la Comisión ad hoc y la retención de algunos misiles. El FMLN y el gobierno negociaron dos acuerdos, el 22 de diciembre de 1992 y el 4 de febrero de 1993. En el primero, el FMLN aceptó el traslado de dos grupos de policías a la Policía Nacional Civil, los cuales eestaban parcialmente integrados por personal militar, previa evaluación e instrucción. Se trataba de la Comisión Investigadora de Hechos Delictivos (CIHD) y la Unidad Ejecutiva Antinarcóticos (UEA). En el segundo acuerdo, el FMLN aceptó postergar la renuncia de ciertos ofi-

19. Marrack Goulding, "The Evolution of United Nations Peacekeeping", Intemational affairs, Vol. 69, № 3, 1993, p. 458. Citado en Eva Bertram, "Reinventing Governments". Una articulación anterior y más estrecha de este dilema respecto a las tensiones entre la verificación de los derechos humanos y los roles diplomáticos de las Naciones Unidas aparece en Human Rights Watch - Americas, "Peace and Human Rights: Successes and Shortcomings of the U.N. Observer Mission in El Salvador (ONUSAL)", Vol. 4 , N ${ }^{\circ}$ 8, 2 de septiembre de 1992, asf como en el capitulo sobre El Salvador de The lost agenda: Human Rights and United Nations Field Operations, Nueva York, junio de 1993. 
ciales del ejército del nivel superior 20 . A cambio de estas concesiones, el FMLN recibió un paquete de capacitación, becas y créditos para 600 ex comandantes guerrilleros de nivel medio, y además, la transferencia de ciertos lotes de tierra para sus beneficiarios ${ }^{21}$. Ambos acuerdos tendrían consecuencias negativas duraderas: la presencia de la Comisión Investigadora de Hechos Delictivos (CIHD) y la Unidad Ejecutiva Antinarcóticos (UEA) en la Policía Nacional Civil perjudicaron su desarrollo y la permanencia prolongada de la dirigencia militar intransigente en el ejército retrasó las reformas militares y contribuyó a que se descuidaran los programas sociales para los soldados desmovilizados 22 .

Es importante notar que estos tres acuerdos se hicieron sin la mediación de las Naciones Unidas, en gran parte porque ésta, como defensora de los principios de las recomendaciones de la Comisión ad hoc, no estaba dispuesta a hacer concesiones23. En efecto, al insistir más que las propias partes en lo que respecta a los compromisos adquiridos en los acuerdos específicos, este organismo se marginó temporalmente, aunque en realidad casi no le quedaba alternativa. Aceptar mediar en estas pláticas hubiera podido socavar su autoridad moral como agente de principios; además, es poco probable que la Comisión Investigadora de Hechos Delictivos alterara el resultado, en vista de que cada una de las partes tenía incentivos fuertes para realizar tales acuerdos.

A la larga, el purismo de las Naciones Unidas dio resultados. En particular, ayudó a rescatar a la nueva policía civil del impacto desastroso causado por el traslado de la Comisión Investigadora de Hechos Delictivos y la Unidad Ejecutiva Antinarcóticos, el cual había sido aceptado por el FMLN, en el acuerdo del 22 de diciembre de 1992. Contrario a las condiciones estipuladas en dicho acuerdo, la evaluación realizada fue mínima, no se impartió ninguna instrucción a los agentes y algunos de ellos, aunque carecían de la educación y capacitación necesarias para ejercer roles de liderazgo en la policía civil, fueron nombrados oficiales al ingresar a la Policía Nacional Civil. A finales de 1993, una cantidad de ex oficiales de la Unidad Ejecutiva Antinarcóticos se había apropiado de los puestos de mando fuera de su área de especialización, así eludieron el entrenamiento de la academia y los requisitos de educación exigidos a los oficiales de la Policía Nacional Civil cuando éstos ingresan por la vía normal. Pronto, éstos agentes se convirtieron en una influencia corrosiva y militarizante dentro de la nueva fuerza. Ex agentes y ex oficiales de la Unidad Ejecutiva Antinarcoticos surgieron como los violadores más frecuentes de los derechos humanos dentro de La Policía Nacional Civil. La ex Comisión Investigadora de Hechos Delictivos, transformada en la División de Investigaciones Criminales, se desempeñó me-

20. La depuración del alto mando militar no se completó sino hasta que el último de los oficiales completó sus treinta años de servicio y se retiró de acuerdo con los procedimientos militares nomales, el 30 de junio de 1993. Entrevista a un funcionario de las Naciones Unidas, mayo de 1995.

21. El Ejército Revolucionario del Pueblo (ERP) y la Resistencia Nacional (RN) se conocen como los partidarios principales de este convenio, por encima de las objeciones iniciales de otros grupos del FMLN. Entrevistas con USAID y funcionarios de las Naciones Unidas, julio de 1993. Esta negociación cré muchas divergencias dentro del FMLN, aunque públicamente se logto mantener una postura unificada, pero incidió en sembrar las semillas de la división posterior. Ver Blue Book, documento 84. La firmeza de las Naciones Unidas respecto al tema de la Comisión ad hoc también proporcionó al FMLN (aunque no intencionalmente) una influencia política para negociar beneficios que de otra manera no podría haber obtenido.

22. Tanto los funcionarios de las Naciones Unidas como ex soldados descontentos reclamaban que el antiguo alto mando, encabezado por el general René Emilio Ponce, se oponía particularmente a proporcionar beneficios a los ex soldados y prefeŕa destinar los fondos del Ministerio de la Defensa a otros usos. La falta de ayuda para la "reinserción social" de los ex soldados condujo a protestas violentas y a la toma de rehenes. Entrevistas con funcionarios de las Naciones Unidas y líderes de la Asociación de Soldados Desmovilizados de las Fuerzas Armadas de El Salvador, junio y julio de 1995.

23. El jefe de misión de ONUSAL estuvo presente durante algunas negociaciones, pero no participó como mediador. Entrevista a un funcionario de las Naciones Unidas, mayo de 1995. 
diocremente, y sus miembros estuvieron implicados en actividades criminales, incluso en el asesinato de Francisco Velis, líder prominente del FMLN.

Ante esta situación en deterioro, ONUSAL adoptó una posición cada vez más firme en 1994. determinando que los ex funcionarios de la Unidad Ejecutiva Antinarcóticos sólo podían trabajar dentro de la División Antinarcotráfico (DAN) de la Policía Nacional Civil, y que todo ex integrante de la Unidad Ejecutiva Antinarcóticos y de la Comisión Investigadora de Hechos Delictivos debería asistir a un curso completo de entrenamiento en la academia. Cuando, a finales de 1994, el gobiemo por fin aceptó estas medidas, los miembros de ambos grupos se pusieron en huelga $y$, por último, renunciaron a la policía.

Con su postura purista en estos asuntos, ONUSAL hizo una contribución positiva al desarrollo de la Policía Nacional Civil y demostró que, bajo ciertas circunstancias, la Organización de las Naciones Unidas puede neutralizar con éxito las concesiones imprudentes entre las partes. Pero es importante entender las circunstancias. La efectividad de las Naciones Unidas en cuanto a la policía dependía de una mayor coordinación entre los donantes internacionales y las consideraciones políticas nacionales de dos presidentes salvadoreños sucesivos. Con el "programa de trabajo" del 19 de mayo de 1994, se abrió la puerta para que este organismo desempeñara un rol de verificación más activo en lo relativo a la policía. En dicho programa, el gobierno y el FMLN solicitaban a ONUSAL una evaluación sustancial de los esfuerzos de la Policía Nacional Civil y de la Academia Nacional de Seguridad Pública hasta la fecha. Después de más de un año, el gobierno de Calderón invitó a la misión (MINUSAL) a hacer una evaluación exhaustiva complementaria de las nuevas instituciones de seguridad pública24. Aparentemente, en alguna medida, estos logros fueron consecuencia de la mayor coordinación entre las misiones de las Naciones Unidas y los donantes internacionales, en particular los Estados Unidos, quienes utiliza- ron su influencia económica para reforzar la crítica y la presión privada con el fin de obtener acceso a información detallada acerca de la Policía Nacional Civil. El momento oportuno para establecer el acuerdo gubernamental, que determinó la expansión del rol de las Naciones Unidas, en parte, se puede atribuir al hecho de que la cooperación y coordinación entre ONUSAL y los donantes no se desarrollaron, sino hasta más tarde en la vida de la misión 25 .

Los factores internos que no estaban bajo el control de los actores internacionales también tuvieron un rol crucial en este caso. Entre éstos estaban el anhelo del presidente Cristiani por finalizar su período dejando una buena impresión en la comunidad internacional y el hecho de que con las elecciones concluidas y la posición política hegemónica de ARENA bien establecida, Cristiani ya no debía preocuparse por ofender a los electores más conservadores y nacionalistas de su partido, al hacer concesiones en la seguridad pública. Además, el presidente entrante, Calderón, necesitaba apoyo internacional para restaurar su imagen $y$, por lo tanto, tenía motivos para hacer concesiones ante la preocupación de las Naciones Unidas en relación con la policía. Hasta que las autoridades de seguridad pública cambiaron, a mediados de 1994, la Organización de las Naciones Unidas pudo contar con la colaboración necesaria para hacer realmente sus diagnósticos.

Estos ejemplos ilustran de forma muy significativa cuán fuertemente influyen las condiciones domésticas en la habilidad de las Naciones Unidas para enfrentar los desafíos de la verificación. En primer lugar, el riesgo de parecer parcial fue superado por la capacidad de la misión para proporcionar una ayuda invaluable en forma de mediación y arbitraje, en una situación en donde las soluciones negociadas aún interesaban a ambas partes. En segundo lugar, cuando los motivos de las partes implicadas eran contrarios a los de las Naciones Unidas, esta organización no podía hacer nada. Por último, cuando el gobierno debilitado a nivel internacional pidió el apoyo de un ente verificador

24. Dos documentos fueron proporcionados al gobiemo, el 15 de julio de 1994 y el 28 de septiembre de 1995.

25. Desafortunadamente esta cooperación llegó cuando el proceso ya estaba avanzado. Ver Gino Costa, Police reform in El Salvador, un trabajo presentado como conferencia titulada "The International community and police reform in Central America and Haiti", Washington, D.C., 3 y 4 de noviembre de 1994; ver también William Stanley, Protectors or perpetrators? The institutional crisis of the salvadoran civilian police, Washington, D.C. y Cambridge, Washington Office on Latin America and Hemisphere Initiatives, enero de 1996. 
de las Naciones Unidas, ésta finalmente fue capaz, con la ayuda de la condicionalidad de los donantes internacionales, de llevar a cabo sus funciones de verificación de una manera sorprendentemente exhaustiva.

\subsection{Dependencia de las partes para obtener in- formación}

Al verificar los acuerdos, la Organización de las Naciones Unidas a menudo careció de mecanismos independientes para obtener más información que la que podían ofrecer las partes. Esto expuso a la misión a dos posibles riesgos: las partes podían mentirle, tal como lo hizo el FMLN en relación con su inventario de armas, o las partes podían simplemente excluirla, impidiéndole la verificación, tal como lo hizo el gobierno con los programas de reinserción para los ex soldados. Ambos casos fueron potencialmente desestabilizadores, lo cual elevó los riesgos potenciales para las Naciones Unidas. No obstante, en ambos casos ONUSAL reaccionó ante estos problemas no haciendo nada $y$, finalmente, ambos fueron resueltos por fuerzas fuera de su control.

\section{Desde el principio,} ONUSAL dudó de la exactitud del inventario de armas del FMLN. Información proveniente de otras fuentes, incluyendo los Estados Unidos, sugería que el FMLN poseía una cantidad mayor de armas y que las había más nuevas de las descritas en el inventario. Esto no resultaba sorprendente la mayoría de observadores esperaban que el FMLN conservara algunas armas como garantía-, pero ello colocó a las Naciones Unidas en una posición difícil. Si ONUSAL aceptaba un inventario de armas del cual tenía fuertes sospechas de que estaba incompleto, pondría en peligro su propia credibilidad como verificador, en el caso que se encontraran más armas, y si, por otro lado, cuestionaba las afirmaciones del FMLN y éste insistía en que su inventario estaba completo, de hecho, podría ocasionar la suspensión del proceso de paz.
La misión carecía del aparato investigativo y de inteligencia para descubrir de manera independiente los depósitos de armas del FMLN. Finalmente, la misión aprobó el inventario esperando lo mejor. La explosión accidental, ocurrida en un escondite del FMLN, en Managua, resultó fortuita de muchas maneras: sucedió antes de iniciar la campaña electoral y los costos nacionales e internacionales para el FMLN fueron tan grandes que los ex rebeldes procedieron al desarme total, con lo cual el asunto de las armas fue olvidado.

Los programas gubernamentales de reinserción para los ex soldados presentaron un desafío diferente. Aunque la misión supuestamente debía verificar los programas para los ex combatientes, en la práctica, el gobierno negó a ONUSAL el acceso a la información detallada sobre los programas que se estaban ofreciendo a los soldados desmovilizados. El gobierno consideraba que a él le correspondía la responsabilidad de manejar la reinserción de sus propios ex combatientes 26 . De hecho, los programas gubernamentales eran muy deficientes, en particular aquellos dirigidos a cierta categoría de soldados. A pesar de las súplicas reiteradas que algunos grupos de soldados desmovilizados que no habían sido tomados en cuenta dirigieron al gobierno y a ONUSAL, se adoptaron pocas medidas para favorecerlos.

Por consiguiente, en numerosas ocasiones, éstos recurrieron a la ocupación del edificio de la asamblea legislativa y de otros edificios gubernamentales. Sólo después de la primera de estas acciones, a finales de 1993, cuando los ex soldados tomaron como rehenes a los tres poderes del Estado, el gobierno aceptó comenzar a pagar la indemnización de unos 18,000 soldados desmovilizados 27. El éxito de estas tácticas extra parlamentarias, unido a los retrasos posteriores y la exclusión de los programas, a menudo injusta, de algunos de los soldados, contribuyó a la realización de

26. Entrevista a un funcionario de las Naciones Unidas, julio de 1993.

27. Entrevistas a líderes de la Asociación de Soldados Desmovilizados de las Fuerzas Armadas de El Salvador (ADEFAES), junio de 1995. 
repetidas manifestaciones, en 1994 y 1995, en las cuales participó una gama creciente de ex combatientes, patrulleros civiles y heridos de guerra. En una manifestación que se llevó a cabo a principios de 1995, soldados desmovilizados lograron paralizar la ciudad. La policía, incluso la nueva Policía Nacional Civil, respondió violentamente en varias oportunidades. ONUSAL jugó un rol mediador activo e importante para la resolución de cada uno de estos conflictos. En retrospectiva, aunque la misión dependía del gobierno para obtener información, las crisis podrían haber sido prevenidas o moderadas si la verificación hubiese sido más activa, incluyendo la evaluación de los programas gubernamentales para los ex combatientes.

\subsection{La verificación como fuerza de cambio}

La presencia de una misión de verificación como ONUSAL en un país tan pequeño como El Salvador causó una serie de efectos indirectos. Por ejemplo, la presencia de la misión en el campo disuadía automáticamente las violaciones de los derechos humanos. Más allá de dichos efectos automáticos, el rol verificador de las Naciones Unidas le brindó oportunidades para influenciar de manera deliberada la situación nacional. Entre otras cosas, ONUSAL se planteaba cómo desempeñar su papel público de tal manera que pudiera promover el desarrollo exitoso del proceso de paz y dónde poner los límites a su intervención en la esfera pública. En esta sección se examinarán cuatro de los roles de ONUSAL: la divulgación de información sobre los derechos humanos, la promoción pública de los acuerdos de paz, el impacto de sus investigaciones y la ayuda directa en el empadronamiento.

Es obvio que ONUSAL no aprovechó totalmente el mandato estipulado en los acuerdos de San José en relación con la divulgación de los resultados de su verificación, a través de los medios de difusión, la educación de la opinión pública en derechos humanos y la explicación clara de su propia función. Se hizo poco esfuerzo en publicitar información sobre casos particulares. La misión utilizaba dicha información en sus comunicaciones privadas con el gobierno, pero su principal producto público era una serie de informes para el
Secretario General de las Naciones Unidas. Aunque se tratara de documentos supuestamente públicos, éstos no se difundían con amplitud en El Salvador. No obstante, si este hubiera sido el caso, es cuestionable el valor que esta información hubiera tenido para la opinión pública, ya que se trataba de documentos redactados en un estilo legal formal, inaccesible para la mayoría de los salvadoreños. Los esfuerzos en la educación sobre derechos humanos empezaron tarde, carecían de suficiente financiamiento $y$, en resumen, eran inadecuados para abordar la ignorancia general de la población salvadoreña respecto a sus propios derechos, las responsabilidades de su propio gobierno y el tipo de acción que en forma razonable podrían esperar de ONUSAL. En muy pocas ocasiones ONUSAL ofrecí conferencias de prensa sobre las condiciones o los casos de derechos humanos y, cuando lo hacía, éstas no siempre eran en particular informativas28. En 1993 y 1994, la División de Derechos Humanos mantuvo un perfil más alto en la prensa, a través de numerosas declaraciones públicas de su jefe, el peruano Diego García Sayan, pero esto

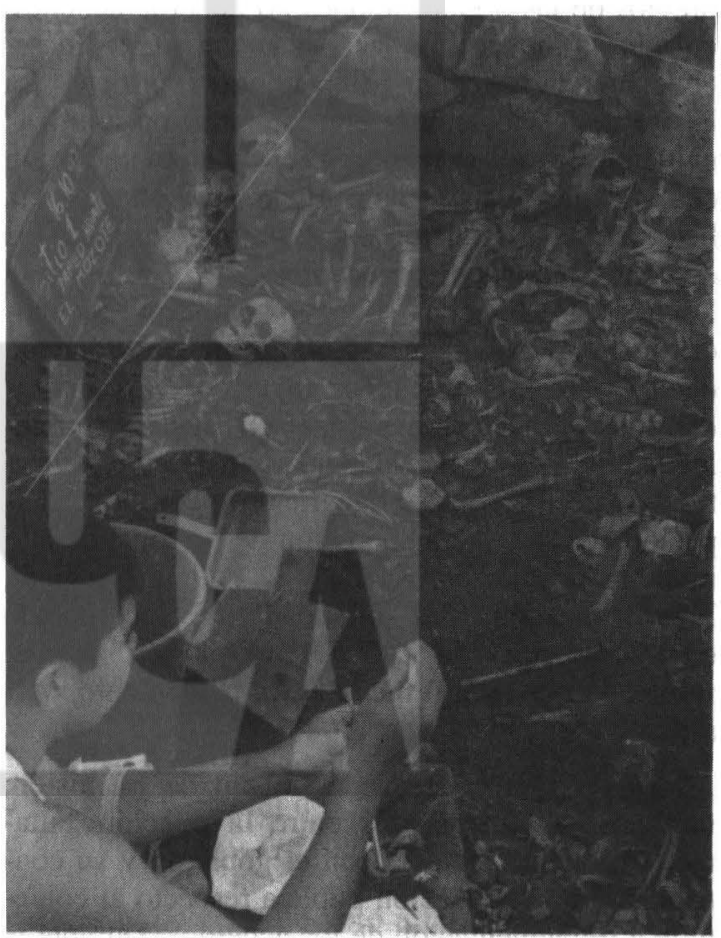

28. Human Rights Watch - Americas, "Peace and Human Rights" y Lawyers Committee, Improvising History, p. 67. 
no fue suficiente para realizar una estrategia completa de información pública.

La reticencia de ONUSAL a hacer declaraciones públicas frecuentes sobre casos específicos de violaciones de los derechos humanos fue una gran oportunidad perdida. Al publicitar ampliamente sus resultados, la misión hubiera podido contribuir en forma importante a transmitir a los salvadoreños un sentido más claro de los criterios de los derechos humanos, internacionales y nacionales, y a aclarar una serie de casos que en apariencia estaban motivados en la política, pero que al llevar a cabo investigaciones adicionales resultaron no tenerlas. La aclaración de dichos casos y la información sobre otros que, de hecho, parecían estar motivados políticamente, podrían haber aumentado la confianza pública en las fases iniciales del proceso de paz.

Una de las razones que explica la prudencia de la misión al publicitar casos fue de índole metodológica: la expectativa inicial de la División de Derechos Humanos, generada por los informes previos de las organizaciones no gubernamentales, era que la mayoría de las violaciones de los derechos humanos tenían motivaciones políticas. La ausencia de violaciones con "motivación política" evidente llevó a la misión a tener una apreciación equivocada de la situación. En efecto, esa ausencia hizo pensar a la misión que las condiciones de los derechos humanos habían mejorado. En 1993, la División de Derechos Humanos empezo a reconocer una modalidad más complicada de violación de los derechos humanos, en la cual los límites entre las organizaciones y las actividades criminales y políticas se mezclaban, y en la cual las estructuras criminales se beneficiaron con la participación activa y la colaboración de personal de alto nivel de la Fuerza Armada y la Policía Nacional. Esta evaluación, más sofisticada, fue incorporada en los informes de ONUSAL y, posteriormente, reforzada por el informe del Grupo Conjunto, presentado a medidados de 199429.

En las demás áreas de trabajo de la misión, también había tensiones entre la relación "altamente política" de ésta con el gobiemo y su contribución a la educación pública respecto al contenido e implementación de los acuerdos. Durante la fase inicial de la misión, ésta tendió a mantener cierto grado de hermetismo alrededor de las negociaciones. Las diferentes "recalendarizaciones" del programa de implementación de elementos clave de los acuerdos eran documentos supuestamente confidenciales aunque, en la práctica, fueron divulgados con amplitud por la prensa a la cual las partes se los entregaron. Esta secretividad era comprensible en 1992, cuando las tensiones eran fuertes y las negociaciones a puerta cerrada a menudo eran ejercicios delicados y vagos, que podían afectar en forma negativa el voto duro de ambas partes, pero después de la desmovilización era menos justificable. Durante la jefatura de Augusto Ramírez Ocampo, el segundo jefe de la misión (1993-1994), ONUSAL hizo numerosos pronunciamientos positivos acerca del progreso de los acuerdos de paz, los cuales no sólo reflejaban la realidad, sino que también minaban la posición de aquéllos dentro de ONUSAL (y del FMLN), puesto que ejercían presión para un cumplimiento más riguroso. Más tarde, por iniciativa del último jefe de la misión, Enrique Ter Horst (1994-1995), ONUSAL empezó a dar a conocer más ampliamente los acuerdos entre las partes, así como también publicó un boletín informativo semanal sobre el estado de cumplimiento de los compromisos adquiridos. La misión también comenzó a compartir más información, a modo de prueba, con algunos periodistas y editores locales más responsables. Esta mayor apertura no tuvo efectos negativos, lo cual indica que quizás podría haberse dado antes.

Aunque las exigencias a corto plazo para mantener relaciones de trabajo con ambas partes eran apremiantes, se puede argumentar que una de las contribuciones de mayor duración potencial de una misión es su capacidad para comunicarse directamente con la opinión pública. Mediante el impulso de la apertura en las negociaciones entre las partes y la proporción de análisis públicos contínuos y confiables acerca del estado de implementación de los diferentes acuerdos, una misión puede contribuir a ofrecer a la opinión pública un discurso más racional, transparente y comprensible.

Uno de los aspectos más desconcertantes de la situación en El Salvador es el grado de compromiso aparente de la población con las reformas

29. Ver el informe publicado el 28 de julio de 1994 por el Joint group for the investigation of politically motivated illegal armed groups (extracto: conclusiones y recomendaciones), Blue Book, documento 113, p. 568-575. 
institucionales, logradas por medio de los acuerdos de paz. En una encuesta reciente, realizada por la Universidad de Centroamericana "José Simeón Cañas", el 76 por ciento de los salvadoreños expresó su conformidad con la siguiente afirmación: "Lo que El Salvador necesita es un hombre fuerte y determinado que imponga el orden". Las grandes mayorías expresan poca confianza en sus funcionarios electos, partidos políticos e instituciones estatales 30 . No obstante esto, por lo menos existe la posibilidad de que una mayor transparencia en las negociaciones para la implementación de los acuerdos, así como un esfuerzo mayor en la educación de la opinión pública por parte de ONUSAL, hayan podido contribuir a aumentar la apreciación de la opinión pública sobre la importancia de los acuerdos y a profundizar su compromiso con los cambios institucionales a que dieron lugar.

Un tercer punto relacionado con los límites de la función de las Naciones Unidas es el uso apropiado de su capacidad investigadora. En los primeros dos años de la misión, la División de Derechos Humanos, por lo general, se limitó a verificar la existencia de violaciones de los derechos humanos, identificar a los responsables, cuando era posible, y determinar si las instituciones estatales respetaban el proceso legal, originado en dichas violaciones. Los grupos de derechos humanos invariablemente se decepcionaban porque ONUSAL no usaba su capacidad investigadora para "resolver" casos importantes de derechos humanos, esto es, identificar a los autores intelectuales y presionar al gobierno y al poder judicial para procesar de manera efectiva a los responsables. Sin embargo, la crisis de los últimos meses de 1993, cuando fueron asesinados varios altos dirigentes del FMLN, lo cual, finalmente, condujo a la formación del Grupo Conjunto para la Investigación de Grupos Armados Ilegales con Motivación Política, hizo que ONUSAL se mostrara más interesada en investigar por su cuenta y presionar para que el sistema judicial resolviera los casos más importantes.

En el caso de la ejecución del líder del FMLN, Francisco Velis, los investigadores de ONUSAL descubrieron a una testigo clave que sabía de la participación de un sargento en servicio activo en la División de Investigaciones Criminales (DIC) de la Policía Nacional Civil. Este descubrimiento, en sí alarmante, planteó dudas acerca de la infiltración adicional de elementos criminales en dicha institución. ONUSAL persuadió a la testigo para que rindiera su declaración, la acompañó al tribunal y ayudó a garantizarle protección dentro del país $y$, posteriormente, en el extranjero. De esta manera, desarrolló, en la práctica, un programa ad hoc para proteger a los testigos 31 . Además, ONUSAL presionó a los tribunales, a los acusadores y a la misma Policía Nacional Civil para que el acusado, un funcionario de la misma policía, fuese arrestado. La lentitud con la que procedieron las autoridades salvadoreñas y la divulgación de información por parte de ellas mismas permitieron que el sospechoso escapara a los Estados Unidos. Más tarde, fue capturado y extraditado a El Salvador donde espera ser juzgado.

En este caso tan importante de derechos humanos se pudo avanzar únicamente por la actividad independiente de ONUSAL, la cual investigó y verifico, lo cual demuestra de forma tangible la falta actual de voluntad política por parte de los actores nacionales para esclarecer los casos importantes de violación de los derechos humanos. Pero, ¿fue demasiado lejos la Organización de las Naciones Unidas? Por ejemplo, si las medidas de protección de ONUSAL resultaran insuficientes y la testigo que debió ser convencida para rendir su declaración hubiera sido asesinada, ¿cuál habría sido la respuesta a la pregunta anterior? Una verificación tan activa de los casos sólo es sostenible en un clima donde las respectivas instituciones estatales también están claramente interesadas en obtener resultados. En este caso no había un interés notorio. Sólo el tiempo dirá si la intervención de ONUSAL en este caso sentó un precedente importante para que las instituciones locales siguieran su ejemplo.

ONUSAL también participó en forma muy directa, y más allá del mandato verificador que había recibido, en el proceso de empadronamiento. A mediados de 1993, en vísperas de la apertura de la División Electoral de ONUSAL, se hizo evidente que el proceso de empadronamiento no estaba avanzando con la suficiente rapidez como para permitir el derecho de voto a nuevos electores, en

30. ONUSAL fue clausurada formalmente a finales de abril de 1995 y fue reemplazada por una misión mucho más pequeña, llamada MINUSAL, dirigida en sus inicios por Enrique Ter Horst.

31. Lawyers Committee, Improvising History, p. 74. 
especial entre los electores potenciales del FMLN, el cual se había integrado hacía poco tiempo en el sistema político, como un partido político legal 32 . Aparentemente, el Tribunal Supremo Electoral sólo hacía esfuerzos simbólicos para mejorar el proceso, no obstante que los Estados Unidos había retenido la ayuda y la gran presión ejercida por otros actores internacionales, incluyendo ONUSAL. La influencia de la comunidad internacional era limitada, porque los acuerdos de paz no proporcionaban directrices firmes y específicas para reformar el Tribunal Supremo Electoral, el cual estaba necesariamente sometido a la influencia de los partidos políticos, y, tal como se observó antes, los partidos que lo controlaban tenían razones internas poderosas para no ampliar el espectro de electores potenciales de la oposición. Ante estas circunstancias y ante la disponibilidad fortuita de más de 200 policías de las Naciones Unidas, subempleados por la suspensión del trabajo con la Policía Nacional Civil (ver más adelante), ONUSAL decidió destinar la mayor parte de sus recursos humanos y físicos al empadronamiento. Los observadores de ONUSAL trabajaron en forma simultánea con los empleados del Tribunal Supremo Electoral, y prestaron importantes servicios logísticos y de comunicaciones, incluso, sacaron fotocopias. A lo largo del proceso, el personal de ONUSAL se convirtió en una especie de apéndice del Tribunal Supremo Electoral33.

Sin lugar a dudas, ONUSAL superó su mandato de verificación al ofrecer esta ayuda, lo cual puede haber afectado su rol verificador. Sin embargo, la decisión pudo haber sido acertada, puesto que todo el proceso de paz dependía de la libertad y limpieza de las elecciones así como también de su aceptación por los partidos políticos y la población en general. Sin el apoyo de ONUSAL y de otros actores importantes, como el Alto Comisio- nado de las Naciones Unidas para Refugiados, que ayudó a los ciudadanos de las antiguas zonas conflictivas a obtener sus documentos de identidad, y la Agencia Internacional para el Desarrollo, que proporcionó asistencia técnica al Tribunal Supremo Electoral y financió el trabajo de organizaciones no gubernamentales para educar a los votantes $y$ pormover el empadronamiento, las elecciones podrían haber sido más cuestionadas de lo que lo fueron en la primera vuelta de la elección presidencial.

Se podría argumentar que la participación direcla de ONUSAL en las tareas del Tribunal Supremo Electoral podría haber llevado a que aquélla a descuidar sus responsabilidades de verificación y al mismo tiempo habría proporcionado a éste "un certificado de buena salud". Sin embargo, la evidencia de que este potencial conflicto de intereses hubiese afectado el trabajo de ONUSAL es limitada. Los informes de la División Electoral, aunque elaborados en un lenguaje diplomático, analizaban con precisión los problemas del Tribunal Supremo Electoral. Al final, esta cuestión resultó irrelevante. No existe evidencia como para sugerir que una crítica más intensa hubiera generado cambios en el Tribunal Supremo Electoral. A pesar de las deficiencias en el método de verificación de ONUSAL el día de las elecciones, las cuales impidieron evaluar de manera sistemática las irregularidades, nadie ha demostrado hasta ahora que éstas hayan alterado en forma importante el resultado electoral, con la posible excepción de unos cuantos municipios 34 . Otra verificación de ONUSAL, menos notoria, pero muy importante, fue la encuesta de salida que hizo el día de las elecciones. Esta medida probablemente ayudó a evitar que ARENA hiciera declaraciones triunfalistas en la primera ronda de la elección presidencial, dado el margen de Calderón 35.

32. Entrevistas con diferentes funcionarios de ONUSAL, enero- junio de 1995.

33. Madalene O_Donnell, Jack Spence y George Vickers, El Salvador elections 1994: the voter registraton tangle, Cambridge, Hemisphere Initiatives, julio de 1993; Madalene O'Donnell, El Salvador elections 1994: voter registration progress and the tasks ahead, Cambridge, Hemisphere Initiatives, noviembre de 1993.

34. Algunos funcionarios de ONUSAL se refirieron irónicamente a estas tareas como "trabajo de hormiga". Ver Tommie Sue Montgomery, "Good observers, bad leaders, and ugly politics: observing elections in El Salvador", trabajo presentado en una conferencia titulada "Peacemaking and democratization in the hemisphere: multilateral approaches", North-South Center, Miami, 11-13 de abril de 1996, p. 26.

35. Ver Jack Spence, David Dye y George Vickers con Garth David Cheff, Carol Lynne D_Arcangelis y Ken Ward, El Salvador_s elections of the century: results, recommendations, analysis, Cambridge, Hemisphere Initiatives, julio de 1994. Esto también es reconocido por Félix Ulloa, quien como miembro del Electoral Vigilance Board, quizás haya sido el crítico más directo del Tribunal Supremo Electoral, y quien, como magistrado del mismo, electo en 1994, continuó manteniendo su juicio. Entrevista, julio de 1995. 
4. Desafios para las Naciones Unidas: el fortalecimiento institucional

\subsection{Acceso}

El acuerdo de San José sobre derechos humanos no estipuló claramente el fortalecimiento de las instituciones del Estado relacionadas con la protección de los derechos humanos (la policía, los tribunales, el procurador de los derechos humanos). La única excepción fue una mención vaga sobre la necesidad de que la Organización de las Naciones Unidas prestara su apoyo a las autoridades judiciales. Esta laguna en el mandato inicial de ONUSAL, limitando su patrón inicial de intervención, refleja el hecho de que esta organización, al igual que las organizaciones no gubernamentales en general, posee más experiencia en la interpretación de la ley sobre derechos humanos que en el trabajo con instituciones estatales, orientado a mejorar la práctica y la implementación real de las normas de tales derechos. Los expertos de las $\mathrm{Na}$ ciones Unidas que ayudaron a redactar los acuerdos de San José no incluyeron un mandato específico para el fortalecimiento institucional. Para el personal de ONUSAL, el fortalecimiento institucional fue una ocurrencia tardía, motivada por el creciente reconocimiento de que las actividades de verificación por sí solas no tendrían un impacto duradero, a menos que fueran acompañadas por cambios duraderos en las instituciones estatales.

En parte como consecuencia de esta carencia de un mandato preciso para promover el fortalecimiento institucional, algunas intervenciones de las Naciones Unidas comenzaron demasiado tarde para ser plenamente efectivas. Por ejemplo, los cursos de capacitación sobre derechos humanos para jueces, fiscales y policías fueron iniciados hasta muy avanzada la misión, razón por la cual la contribución de ONUSAL ha sido caracterizada por algunos observadores como "muy poco y muy tarde", comparada con la que podría haber hecho, considerando los conocimientos y la experiencia del personal de la misión ${ }^{36}$. No obstante estas críticas, algunas de las actividades de las Naciones Unidas para promover el fortalecimiento institucional dieron inicio desde temprano y algunas tuvieron bastante éxito, a pesar de su corta duración. Entre las más importantes se destaca la participa- ción directa y práctica del personal internacional en el trabajo diario de nuevas instituciones, incluyendo la Policía Nacional Civil y la Procuraduría para la Defensa de los Derechos Humanos.

Ciertamente, la falta de conciencia inicial de la misión respecto a la necesidad de fortalecer las instituciones contribuyó a que sus esfuerzos se retrasaran, aunque muchas de las limitaciones principales eran ajenas a ONUSAL. La limitación más evidente fue el hecho de que dos de las instituciones más importantes, necesitadas de fortalecimiento institucional, la Policía Nacional Civil y la Procuraduría para la Defensa de los Derechos Humanos, nacieron hasta después del primer año de existencia de la misióı. Sin embargo, lo que es más importante, la misión no podía implementar proyectos de fortalecimiento institucional, a menos que el gobierno, y más específicamente las instituciones mismas, estuvieran dispuestas a aceptar la ayuda de ONUSAL. En la práctica, la receptividad variaba según la institución y con el paso del tiempo, algunas instituciones cambiaron su postura en forma abrupta en relación con la ayuda que ONUSAL les podía prestar. Por ejemplo, al principio, la Policía Nacional Civil estaba bastante abierta a recibir ayuda de ONUSAL, pero luego, la nueva dirigencia de la institución decidió tomar distancia de la misión, en un período crucial de nueve meses. ONUSAL recobró su papel de asesora cuando la dirección de la policía volvió a cambiar. El Procurador para la Defensa de los Derechos Humanos mantuvo a ONUSAL a cierta distancia, pero después, en los últimos meses de su mandato, solicitó ayuda a la misión. Los magistrados de la Corte Suprema de Justicia redujeron al mínimo las posibilidades de colaboración de ONUSAL con el sistema judicial.

El trabajo de ONUSAL para fortalecer institucionalmente a la Policía Nacional Civil, el cual tuvo mucho éxito, pero duró muy poco, se debió a que la misión asumió, de hecho, todas las responsabilidades de la institución en algunos lugares del país. El retraso que experimentó la fundación de la Policía Nacional Civil no le permitió hacer acto de presencia en las antiguas zonas conflictivas, donde la guerrilla había sido desmovilizada. Sin embargo, la mayoría de los habitantes de estas zonas temían las incursiones amenazadoras de ex agentes de

36. Entrevista con funcionario de ONUSAL, septiembre de 1994. 
la antigua Policía Nacional. ONUSAL negoció una solución provisional con las partes, según la cual cadetes de la academia de policía (conocidos como Policía Auxiliar Transitoria) fueron comisionados, después de sólo un mes de capacitación, para patrullar dichas áreas bajo la supervisión directa de la policía de ONUSAL, que también les impartía instrucción diaria en técnicas policiacas. Este rol, potencialmente irritante, fue aceptado por ambas partes porque ONUSAL ya estaba desplegada en todo el país y se había establecido como fuerza confiable e imparcial, porque se la consideraba sólo como sustituto y no como medida permanente y porque nadie más podía jugar ese rol en el período de transición. A pesar de los posibles problemas prácticos que pudieran presentarse, ambas partes consideraron efectiva la función de ONUSAL en relación con la Policía Auxiliar Transitoria.

Aunque el mandato de ONUSAL no establecía específicamente ayudar a la Policía Nacional Civil, la experiencia con la Policía Auxiliar Transitoria preparó el camino a un "programa de instrucción de campo" para la Policía Nacional Civil. De esta manera, ONUSAL y los observadores especializados en el área legal proporcionaron apoyo técnico y logístico a la Policía Nacional Civil cuando ésta empezó a desplegarse, en febrero de 1993. Este esfuerzo, aunque pudo haber sido mejor coordinado, arrojó resultados positivos mientras duró. Los observadores de ONUSAL verificaron las actividades de los recién desplegados agentes de la Policía Nacional Civil, a menudo les dieron asesoría técnica y capacitación en el mismo lugar y de manera simultánea informaron periódicamente a las autoridades de la institución y la Academia Nacional de Seguridad Pública. Un observador cercano anotó que este programa "posibilitó a sus receptores el aprovechamiento de información fresca del campo respecto a los defectos de la capacitación recibida en la academia - en donde la influencia directa de ONUSAL era mínima- y a los problemas operativos de la Policía Nacional Civil", y permitieron que las autoridades pertinentes hicieran los ajustes necesarios 37 . Este programa era ampliamente considerado como beneficioso para la nueva fuerza pública inexperta y fue un importante complemento para los esfuerzos bilaterales, como el Programa de Asistencia para Capacitación en Investigaciones Criminales Internacionales del Departamento de Justicia de los Estados Unidos (ICITAP), que trabajaba con la Policía Nacional Civil y la academia de policía. La capacidad de ONUSAL para ayudar a la Policía Nacional Civil con sus vehículos y radiocomunicaciones contribuyó a compensar la falta de estos artículos en los primeros meses del despliegue de la Policía Nacional Civil.

Desafortunadamente, la asesoría de campo de ONUSAL fue suspendida después de sólo seis meses, al parecer por orden del recién nombrado director adjunto de la misma, un controvertido ex oficial militar, obligado a retirarse antes de finalizar el gobierno de Cristiani, en mayo de 1994. Cuando el camino para restablecer una relación laboral estrecha con ONUSAL quedó despejado, la división de policía de la misión empezó a ser reducida y ésta perdió su capacidad para proporcionar una ayuda práctica significativa a la Policía Nacional Civil, la cual, en esos momentos, se estaba desarrollando con rapidez.

Un segundo esfuerzo efectivo, aunque tardío, para el fortalecimiento institucional, comprendió a la Procuraduría para la Defensa de los Derechos Humanos. En 1994, pocos meses antes de que finalizara el período del procurador, cuando ya había comenzado el retiro gradual de ONUSAL, policías y expertos en asuntos legales se hicieron presentes diario en las oficinas centrales y regionales de la Procuraduría. Todas las denuncias empezaron a ser verificadas en forma conjunta por ambos órganos. Esta colaboración directa entre entidades internacionales y nacionales se convirtió en un seminario permanente para aprender a realizar investigaciones en derechos humanos. Se puede afirmar que esta fue la herramienta más efectiva que ONUSAL pudo ofrecer para fortalecer a la Procuraduría para la Defesna de los Derechos $\mathrm{Hu}$ manos. Sin embargo, a pesar de su éxito y aceptación por la recién electa (y ampliamente respetada) Procuradora, Victoria de Avilés, en marzo de 1995, el programa fue suspendido cuando ONUSAL se convirtió en MINUSAL, en gran parte, debido a un seguimiento inadecuado y las luchas internas entre el personal de las Naciones Unidas 38 .

37. Lawyers Committee, Improvising History, pp. 93-118.

38. Gino Costa, "The U.N. and reform of the police in El Salvador", Intermational peacekeeping, Vol. 2, N 3, 1995, p. 377. 
En vista de los logros aparentemente positivos del trabajo de ONUSAL con la Procuraduría para la Defensa de los Derechos Humanos, aunque por breve tiempo, el retraso de dos años en la aplicación de programas de fortalecimiento institucional parece en particular lamentable. La Procuraduría, después de todo, se encargó de las funciones de supervisión de los derechos humanos que antes correspondía a ONUSAL, cuando ésta abandonó el país. Ayudar al desarrollo de la Procuraduría para la Defensa de los Derechos Humanos obviamente habría sido una gran prioridad. La causa fundamental del distanciamiento entre las dos organizaciones fue la resistencia personal que el procurador, Carlos Molina Fonseca, presentó ante la interferencia externa. ONUSAL, en un esfuerzo por ganarse a Molina y abrirse paso en la institución, trató con bastante suavidad a la Procuraduría en sus informes, hasta que, en agosto de 1994, la División de Derechos Humanos publicó el informe $\mathrm{N}^{\circ}$ 11. Sólo entonces Molina entendió que estaba arriesgando el rechazo de ONUSAL (y de los donantes internacionales) a su reelección. A partir de entonces se mostró más receptivo a la ayuda externa.

En contraste con la experiencia en la Procuraduría para la Defensa de los Derechos Humanos, donde ONUSAL por lo menos pudo colaborar en su fortalecimiento institucional por un tiempo corto, en los tribunales y el ministerio público casi no pudo hacer nada significativo en esta línea. Tal como sucedió con la demora en la Procuraduría para la Defensa de los Derechos Humanos, el distanciamiento existente entre ONUSAL y el sistema judicial se atribuye de manera fundamental a que los principales actores nacionales querían mantener a la misión en su sitio. En este caso, la resistencia principal la presentó el presidente de la Corte Suprema de Justicia, Mauricio Gutiérrez Castro, quien ejercía un control vertical sobre todo el aparato judicial39. Gutiérrez Castro cuestionó la validez del mandato de verificación de ONUSAL en cuanto al poder judicial, argumentando que el poder judicial no era signatario de los acuerdos de paz. Por lo tanto, hubo que esperar a que se eligiera una nueva Corte Suprema de Justicia, lo cual sucedió en 1994. Este hecho fue desafortunado por lo que a ONUSAL se refería. La nueva Corte, más pluralista y abierta a los intentos por reformar el sistema judicial, empezó un proceso de depuración lento, pero seguro, de jueces corruptos o incompetentes, fundamentado, en parte, en los resultados de las actividades previas de verificación de ONUSAL. Desafortunadamente, cuando la nueva Corte Suprema tomó posesión, la misión de las Naciones Unidas ya no contaba con recursos humanos ni con tiempo para contribuir en forma significativa a la reforma del sistema judicial.

Una segunda área donde la contribución al fortalecimiento institucional de ONUSAL fue decididamente limitada fue en el campo de las organizaciones no gubernamentales locales. La ausencia de buenas relaciones de trabajo de la misión con las organizaciones no gubernamentales locales es bien conocida. De ahí que estas últimas sostengan críticamente que ONUSAL no aprovechó la oportunidad para acercarse a las organizaciones no gubernamentales, ayudándolas a mejorar su capacidad para investigar e informar, lo cual, por otro lado, reforzó sus sospechas de que el trabajo en derechos humanos de la misión estaba motivado por consideraciones políticas de alto nivel40. Las organizaciones no gubernamentales de derechos humanos antagonizaron frecuentemente con ONUSAL, criticando su poca disposición para mostrarse firme en sus informes e incluso beligerante en cuanto a condenar los supuestos abusos gubernamentales.

Si bien, por un lado, era obvio que las relaciones de ONUSAL con las organizaciones no gubernamentales a nivel nacional podrían haber sido mejores, por otro lado, a nivel regional, las relaciones eran más productivas y alentadoras. El an-

39. Entrevistas a funcionarios de las Naciones Unidas.

40. Los acuerdos no se tradujeron en reformas inmediatas en la Corte Suprema de Justicia. Estipularon la selección futura de los magistrados de la Corte Suprema, mediante un proceso de nominación a cargo de los miembros de la profesión legal y la aprobación por una mayoría calificada de la asamblea legislativa. Esto forzó a seleccionar candidatos aceptables dentro de un espectro político más amplio y dificultó que una de las partes pudiese controlar la Corte Suprema. Estas reformas fueron aún más cruciales porque el sistema judicial está controlado directamente por la Corte Suprema de Justicia, una característica institucional que ha sido criticada por muchos observadores internacionales. 
tagonismo de algunos organizaciones no gubernamentales hacia ONUSAL se debía a varios factores, incluyendo la sensación de que éste excluía a aquéllas de un terreno que habían ocupado durante más de una década (probablemente una consecuencia inevitable de una fuerza externa a la verificación), y su reacción negativa porque sus propias conclusiones sobre los casos de derechos humanos (los cuales durante la guerra, a menudo, fueron muy politizados) eran analizados por una autoridad más profesional y confiable.

La debilidad principal de la crítica de las organizaciones no gubernamentales nacionales e internacionales consiste en asumir que un mayor esfuerzo por parte de ONUSAL significara automáticamente mayores posibilidades para su propio fortalecimiento. Esta actitud refleja el tabú tradicional de las organizaciones internacionales de derechos humanos ante la crítica de los grupos locales de derechos humanos. La presunción a favor de las organizaciones no gubernamentales se adelanta a una cuestión importante: ¿qué organizaciones no gubernamentales deben ser fortalecidas y con qué criterios se pueden determinar las condiciones en las cuales la Organización de las Naciones Unidas debiera aspirar a apoyarlas? Durante su relativamente corta existencia, ONUSAL no podía superar defectos históricos como la escasez de profesionales del derecho capaces, que pudieran ayudar a las organizaciones no gubernamentales a pasar de la denuncia al compromiso con el proceso judicial o a superar la corrupción y el faccionalismo político41. Aunque podía prestar asistencia técnica, ONUSAL no podía rehacer la es- tructura política orgánica de aquellas organizaciones no gubernamentales con más de una década de historia42.

\subsection{Interacción entre verificación y fortaleci- miento institucional}

El ejemplo antes citado de la Procuraduría para la Defensa de los Derechos Humanos revela una dificultad esencial que la Organización de las $\mathrm{Na}$ ciones Unidas ha enfrentado en su esfuerzo para promover el fortalecimiento institucional: ¿cómo equilibrar un enfoque alentador para avanzar en el fortalecimiento institucional con otro de carácter negativo en cuanto guardián, por otro lado, necesario para la verificación? ¿Existe conflicto de intereses cuando la entidad encargada de la verificación de los acuerdos firmados por las dos partes desarrolla simultáneamente una relación estrecha con sólo una de ellas, por lo general, el gobierno?43. La misma duda surge a nivel de instituciones específicas, ¿hasta qué punto la misión verificadora puede criticar a ciertas instituciones sin arriesgar su capacidad para participar en esfuerzos constructivos de fortalecimiento institucional?

Existen ventajas y riesgos para un sólo organismo que se desempeña al mismo tiempo como agente verificador $y$ promotor del fortalecimiento institucional. En el caso de la Policía Nacional Civil, hay quienes sostienen que ONUSAL actuó con demasiada lentitud en cuanto a la supervisión y critica adecuada de los abusos públicos de esta institución. Un observador de ONUSAL afirmó que temían que la crítica a la Policía Nacional Civil fuese utilizada por sus enemigos. Por eso, las

41. Ver Lawyers Committee, Improvising History.

42. Por ejemplo, las dos organizaciones de derechos humanos de El Salvador con mayor reconocimiento a nivel internacional, las cuales informaron regularmente acerca de la situación, la Oficina de Tutela Legal del Arzobispado de San Salvador y la Comisión de Derechos Humanos no gubernamental (CDHES), no aceptaron fácilmente los esfuerzos para el fortalecimiento institucional. La Oficina de Tutela Legal, el grupo de derechos humanos más conocido, nunca había estado abierto a la crítica de su metodología. Con el tiempo, se fue distanciando cada vez más de ONUSSAL. La Comisión de Derechos Humanos había estado plagada de problemas de comupción y luchas internas de carácter político (debido a las diferencias entre las distintas fracciones del FMLN). En algún momento, después de cambiar de dirección y experimentar recortes en el financiamiento externo, la Comisión aceptó una tímida iniciativa de ONUSAL para afinar su metodología. Poco después, la Comisión se dividió a lo largo de líneas políticas, suscitando dudas acerca del futuro de los esfuerzos de ONUSAL.

43. Un excelente resumen de los desafíos que enfrentó la Organización de las Naciones Unidas en sus relaciones con las organizaciones no gubernamentales se encuentra en NGOs, The UN \& Global Governance, editado por Thomas G. Weiss y Leon Gordenker, Boulder, Lynne Reiner Publishers, 1996, especialmente el capítulo final, escrito por los editores. 
primeras críticas serias no se hicieron hasta el informe $\mathrm{N}^{\circ} 11$, en agosto de 199444. Sin embargo, esta prudencia en la crítica pública no da cuenta de toda la relación entre la policía y ONUSAL. Por ejemplo, la crítica privada fue responsable, en alguna medida, del distancimiento de la Policía Nacional Civil de ONUSAL, ocurrida en octubre de 1993, y relacionada con los esfuerzos para fortalecerla institucionalmente45. Es muy poco probable que, en esa época, críticas mayores por parte de ONUSAL hubieran podido mejorar su capacidad para supervisar los abusos de la Policía Nacional Civil o para ayudar en su fortalecimiento institucional.

Es importante anotar que el gobierno aceptó como parte del "programa de trabajo" del 19 de mayo de 1994 que ONUSAL vigilara en forma abierta a la Policía Nacional Civil y la Academia Nacional de Seguridad Pública. Esta aceptación tuvo lugar mucho antes de la primera crítica pública y cuando la influencia de ONUSAL supuestamente estaba disminuyendo. Tal como se indicó antes, en gran parte, este progreso fue debido a factores políticos nacionales, aunque también hubiera ayudado una coordinación mejor entre los donantes y ONUSAL. Aunque este nuevo rol no estipulaba medidas específicas para el fortalecimiento institucional, las recomendaciones de ONUSAL superaron la verificación de los abusos de los derechos humanos, y entran en la esfera de las reformas estructurales e institucionales necesarias tanto en la policía como en la academia. Después de más de un año, el gobierno de Calderón invitó a MINUSAL, la misión que reemplazó a ONUSAL, a evaluar de manera exhaustiva las nuevas instituciones de seguridad pública.

También hubo observadores que acusaron a ONUSAL de no cumplir por completo con su responsabilidad de verificar el fortalecimiento institucional de la Procuraduría para la Defensa de los Derechos Humanos. Esta indecisión, a la hora de criticar a la procuraduría, se derivaba, en parte, de un juicio político que aseveraba que hacerlo impli- caría abrir espacio a los enemigos de esta nueva institución clave. Sin embargo, la misión abrió otros canales para criticar a la procuraduría -n concreto, los informes del experto independiente de las Naciones Unidas, Pedro Nikken. Si las señales de desaprobación hubiesen sido emitidas con anterioridad, ONUSAL podria haber ejercido presión sobre el procurador para que éste abriera la institución a la misión más rápidamente.

No obstante, la selección del momento oportuno para hacer la crítica fue probablemente crucial. Si ésta se hubiera hecho antes de que Molina manifestara que carecía de apoyo nacional importante, las cosas podrían haber sido diferentes. La única lección clara es que, en general, la Organización de las Naciones Unidas puede esperar que la dirección de algunas instituciones sacrifique el mejor desempeño de éstas a sus propios intereses personales. Una misión internacional puede lograr un acceso mejor a las instituciones que pretende fortalecer si plantea su estrategia alrededor de los intereses nacionales. Si los comentarios en los cuales ONUSAL desaprobaba la actuación de los dirigentes nacionales hubieran sido acompañados con ofertas de apoyo para que éstos hicieran un trabajo mejor, la misión posiblemente habría encontrado las oportunidades necesarias para reformar la institución con mayor rapidez.

\section{Conclusiones}

El Salvador presentaba un contexto inusualmente favorable para que la Organización de las Naciones Unidas hiciera un esfuerzo en la línea del fortalecimiento de la paz. Los dos signatarios del acuerdo anhelaban genuinamente poner fin a la guerra, una condición que no siempre se da en otras situaciones de conflicto interno. La guerra fue impulsada por fuerzas políticas y económicas, y no por conflictos étnicos, factor que facilitó la finalización de la guerra y la consiguiente convivencia entre ex enemigos. El clima internacional también fue favorable. Gracias a la buena suerte y coordinación de los acontecimientos, el contexto

44. Ver De Soto y Castillo, "Implementation of comprehensive peace agreements: staying the course in El Salvador", Global Governance, Vol. 1, № 2, mayo-agosto de 1995, p. 202. Plantean esto como un conflicto potencial en la discusión del futuro de MINUSAL y las razones por las cuales el Consejo de Seguridad debería permanecer vinculado a la verificación política de los acuerdos de paz.

45. Lawyers Committee, Improvising History, p. 37. 
salvadoreño sólo fue afectado en forma mínima por tres limitaciones principales del poder de las Naciones Unidas, identificadas por Eva Bertram, en su artículo "Reinventando los gobiernos": "los estados miembros son codiciosos", "los estados miembros son inconstantes", y "los estados miembros son parciales" 46 . Tal como se observó antes, los estados miembros, de hecho, fueron bastante generosos en financiar la implementación de los acuerdos, la reconstrucción y la misión misma; los estados miembros mostraron un interés consistente e incansable en la promoción y defensa del proceso salvadoreño; y los Estados Unidos, cuyo apoyo histórico a una de las partes durante la guerra pudo haber generado un interés especial en el proceso, se retiró del centro de atención político e hizo donaciones fuertes para la reconstrucción, la redistribución de tierras y el fortalecimiento institucional postconflicto. En retrospectiva, sería difícil imaginar un clima más favorable.

Aun en estas circunstancias $\tan$ fortuitas, en las cuales las partes tenían un interés fundamental en el éxito del proceso, éstas cambiaban de rumbo, según conviniera a sus intereses políticos secundarios y si los costos eran tolerables. Además, los dirigentes de instituciones específicas, como la Policía Nacional Civil y la Procuraduría para la Defensa de los Derechos Humanos, tenían sus propios intereses que los llevaban a evadir la misión, obstaculizando la verificación y el fortalecimiento institucional que ésta desempeñaba. En algunos casos, el uso selectivo de las críticas expresadas por la misión en el momento oportuno podrían haber neutralizado las resistencias, pero en su conjunto, no obstante su posición inusualmente poderosa en El Salvador, la Organización de las Naciones Unidas tenía recursos limitados para influenciar las motivaciones de los actores nacionales. Además, el que el rol de este organismo fuera tan extenso y multifacético creó tensiones y contradicciones potenciales en la realización de su trabajo.

Nuestra revisión de cómo ONUSAL manejó los diferentes desafíos que enfrentó sugiere las siguientes conclusiones tentativas. Primero, es más probable que los estados y otros actores nacionales toleren críticas considerables si éstas son acompañadas de ofertas prácticas de ayuda. Así, ONUSAL contó con la cooperación del gobierno salvadoreño durante el año 1992, pese a sus fuertes críticas contra éste, porque necesitaba la ayuda de la misión como mediador de los desacuerdos con el FMLN para evitar que el proceso fracasara y porque, en general, necesitaba de la aprobación de la misión para poder recibir millones de dólares en ayuda financiera.

A la inversa, en situaciones en donde la misión desea emprender el fortalecimiento institucional $y$ éste encuentra resistencia en la dirigencia de la institución (como en el caso de Molina Fonseca y la Procuraduría para la Defensa de los Derechos Humanos), la crítica pública puede ser una herramienta útil para que éstos evalúen cuáles son sus intereses más importantes.

Para ello, sin embargo, la capacidad de las Naciones Unidas es limitada. Sus críticas al poder judicial dieron pocos frutos hasta que los magistrados de la nueva Corte Suprema de Justicia ocuparon sus cargos. En este caso, la ONU no tenía influencia directa en la antigua Corte Suprema de Justicia, pero tampoco tenía nada que ofrecer en proporción a las prerrogativas y poderes de los magistrados.

En aquellas situaciones en donde es posible combinar la crítica con la ayuda, una de las claves del éxito parece ser la coordinación efectiva de ambas. Esto sugiere que, debido a las dificultades

46. Eva Bertram, "Reinventing Governments: the promise and perils of United Nations peace building" Journal of conflict resolution, Vol. 39, $\mathrm{N}^{\circ} 3$, septiembre de 1995, pp. 387-418. 
mencionadas, asociadas a la combinación de funciones de verificación y fortalecimiento institucional, las ventajas superan los riesgos. Asociar actividades de fortalecimiento institucional y verificación puede producir resultados positivos superiores a la suma de las dos partes individuales. Sin embargo, esto sólo funciona si ambas partes están sincronizadas políticamente. En algunas ocasiones, la misión disponía de suficientes recursos propios para generar una respuesta positiva ante la crítica. La división de derechos humanos de ONUSAL contaba con el personal y la capacidad para ofrecer ayuda considerable a la procuraduría, por ejemplo, de modo que la coordinación entre la crítica y la oferta condicional de ayuda era relativamente sencilla para la misión. Ahí donde la verificación y el fortalecimiento institucional estaban a cargo de actores internacionales diferentes, el acuerdo sobre los objetivos políticos intensificó la influencia de ambos. Por otro lado, cuando la ayuda no estuvo condicionada según criterios políticos compartidos, la efectividad de la verificación y del fortalecimiento institucional fue reducida.
En general, la lección más importante que se puede extraer de la experiencia de ONUSAL posiblemente sea que, al final, las fuerzas políticas nacionales determinaron los resultados en mayor medida que las acciones de las Naciones Unidas. Los reveses mayores y los avances más importantes del proceso corresponden a los intereses políticos nacionales de los actores, cosa que no debería sorprender. Después de todo, el conflicto salvadoref̃o fue una guerra interna. Quizás el mayor logro de ONUSAL haya sido su sensibilidad y flexibilidad para aprovechar las posibilidades y oportunidades surgidas a nivel nacional, así como en el caso de su intervención para examinar a fondo el funcionamiento de la Policía Nacional Civil, según el mandato estipulado en el acuerdo del 19 de mayo de 1994. Aunque la Organización de las Naciones Unidas no pueda controlar los acontecimientos, puede asegurar un impacto más positivo si conserva la maniobrabilidad que le posibilita sacar el mejor partido posible de las oportunidades proporcionadas por los actores nacionales. 